\title{
Satellite chlorophyll concentration as an aid to understanding the dynamics of Indian oil sardine in the southeastern Arabian Sea
}

\author{
N. Nandini Menon ${ }^{1}$, Syam Sankar ${ }^{1}$, A. Smitha ${ }^{1}$, Grinson George ${ }^{2}$, Saleem Shalin ${ }^{2}$, \\ Shubha Sathyendranath ${ }^{3}$, Trevor Platt ${ }^{3,4, *}$ \\ ${ }^{1}$ Nansen Environmental Research Centre, Cochin 682016, India \\ ${ }^{2}$ ICAR-Central Marine Fisheries Research Institute, Cochin 682018, India \\ ${ }^{3}$ Plymouth Marine Laboratory, Plymouth PL13DH, UK \\ ${ }^{4}$ Jawaharlal Nehru Science Fellow, ICAR-Central Marine Fisheries Research Institute, Cochin 682018, India
}

\begin{abstract}
Coastal waters of Kerala, which form an integral part of the Malabar upwelling zone off the southwest coast of India, constitute an important fishing region for small pelagics. Satellite remote sensing data from 1998-2014 were used to test the hypothesis that fluctuations in the landings of Sardinella longiceps, the major pelagic fish landed in the area designated as the South Eastern Arabian Sea (SEAS), are influenced by seasonal variability in phytoplankton biomass (measured as chlorophyll a [chl a] concentration), under the changing strength of physical parameters such as sea surface temperature (SST), alongshore wind stress, Ekman mass transport, sea level anomaly (SLA) and Kerala rainfall. Multiple linear regression analysis (MLRA) was used to assess the influence of physical forcing mechanisms on chl a concentration on monthly and seasonal scales. We found that SLA, alongshore wind stress, SST and rainfall were ranked 1 to 4 , respectively, and the first 3 factors significantly influenced the chl a concentration of SEAS. Pearson's correlation analysis between monthly chl $a$ and sardine landing (with chl a leading) showed a maximum positive correlation (+0.26) at 2 and 3 mo lags, emphasizing that the influence of chl $a$ on the fishery of $S$. longiceps is seasonal $(\mathrm{r}=0.35$ for seasonal lead-lag correlation) in the coastal waters of SEAS. Variation in phytoplankton biomass, as evidenced by chl a fluctuations, seems to have a decisive role in regulating the physiological condition of larvae spawned during the southwest monsoon season, their juveniles and finally the adults that are recruited into the fishery in the next season. Using the quantity of phytoplankton as a predictive tool will exploit the presumptive trophic link to aid understanding of sardine fishery dynamics in upwelling zones.
\end{abstract}

KEY WORDS: Chlorophyll $\cdot$ Satellite remote sensing $\cdot$ Indian oil sardine $\cdot$ Sardinella longiceps South Eastern Arabian Sea

\section{INTRODUCTION}

Generally, marine ecosystems are thought to be regulated by bottom-up control, emphasizing the importance of phytoplankton as the base of the food web (Frederiksen et al. 2006). Chlorophyll a (chl a) is the major photosynthetic pigment occurring in phytoplankton, so its concentration serves as a con-

${ }^{*}$ Corresponding author: tplatt@dal.ca

§Advance View was available online January 16, 2019 venient index of phytoplankton abundance and biomass, with the additional advantage that it can be measured from space (Platt et al. 2010, Pettersson \& Pozdnyakov 2012). The link between phytoplankton and planktivorous small pelagic fishes is influenced by the physical and chemical features of the habitat (Schwartzlose et al. 1999). Pronounced changes in the yields of small pelagics were studied by Long-

(C) The authors 2019. Open Access under Creative Commons by Attribution Licence. Use, distribution and reproduction are unrestricted. Authors and original publication must be credited.

Publisher: Inter-Research · www.int-res.com 
hurst \& Wooster (1990), who formulated indices relating the total annual sardine catch to environmental factors. However, over time in Indian waters, these indices failed due to large variability in landings and the complex correlations between factors (Madhupratap et al. 1994).

Waters off the southwest coast of India, better known as the Malabar upwelling zone (Bakun et al. 1998), contribute nearly $30 \%$ of the total marine fish catch from India (Manjusha et al. 2013). This area, extending from Ratnagiri in the north to Cape Comorin in the south, is characterized by its annual cycle of upwelling associated with the southwest monsoon (Krishnakumar et al. 2008). The ensuing productivity sustains a lucrative fishery for commercially important pelagic fin fishes such as Indian oil sardine Sardinella longiceps and Indian mackerel Rastrelliger kanagurta (Krishnakumar et al. 2008). The Indian oil sardine is the single largest contributor to the total marine fish landings of India (15\%) (Mohanty et al. 2005). Seasonal, annual and decadal fluctuations have been observed in the fishery of this species, the reasons for which still remain enigmatic.

$S$. longiceps, the model organism of the present study, is an epipelagic fish that forms dense neritic shoals. Although oil sardines are present in waters up to $50 \mathrm{~m}$ depth, most of the fish are caught between the $30 \mathrm{~m}$ isobath and the coast, where they form a major inshore fishery exploited by both traditional and mechanised gears (Manjusha et al. 2013). The spawning and recruitment of oil sardines overlap with the upwelling occurring during the summer monsoon along the Malabar coast. Oil sardines grow rapidly during the first few months and mature early within their life span of about $2.5 \mathrm{yr}$. The age at first maturity occurs at less than $1 \mathrm{yr}$, or about $15 \mathrm{~cm}$ size. Being a zero year class fish, their availability in catch depends on the prevailing environmental conditions during the time of spawning and recruitment to fishery (Jayaprakash \& Pillai 2000). Management of the sardine fishery has several challenges due to its widespread distribution along almost the entire Indian coast, and also as it is closely linked to the economic prosperity and food security of the fishing community (Jayaprakash \& Pillai 2000).

Sardines are planktivorous, with a preference for diatoms, especially the centric diatoms that dominate the phytoplankton community of the Eastern Arabian Sea during monsoon. This enabled us to hypothesize that the fluctuations in the landings of S. longiceps, the major pelagic fish landed in Kerala, are influenced by the seasonal variability in phytoplankton biomass brought about by the changing strength of physical properties such as sea level anomaly (SLA), sea surface temperature (SST), surface winds, Ekman mass transport and Kerala rainfall.

Contrary to the understanding that top-down (consumer-driven) removal of fish biomass can have a strong regulatory effect (Worm \& Myers 2003), midlatitude coastal fisheries appear to be strongly constrained by the magnitude of phytoplankton production (Frank et al. 2006). Hence in the present study, priority is given to chlorophyll concentration and its fluctuations in relation to physical forcing mechanisms. We used statistical analysis of satellite remote sensing data to examine whether fluctuations in the landings of $S$. longiceps from the coastal waters of Kerala could be explained by variability in phytoplankton biomass (chl a), brought about by the changing strength of physical oceanographic drivers such as SLA, SST, surface winds, Ekman mass transport and Kerala rainfall.

\section{MATERIALS AND METHODS}

\subsection{Data}

We used monthly, merged surface chl a data for the period 1998-2014, at $4 \mathrm{~km}$ resolution, from the Ocean Colour Climate Change Initiative (OC-CCI), European Space Agency (Sathyendranath et al. 2017, 2018), available at www.esa-oceancolour-cci.org. OC-CCI chlorophyll data are created by band-shifting and bias-correcting ocean colour data from MERIS, MODIS and VIIRS imagery and matching them to SeaWiFS data, merging the datasets and computing per-pixel uncertainty estimates. Data from Version 3.1 were used, in which extra consideration is given to Case-2 retrievals, by flagging and algorithm choice (based on water type) to improve the validity of the products (Jackson et al. 2017).

Monthly SST data (monthly means of daily means), from 1998-2014 at $25 \mathrm{~km}$ resolution from the European Centre for Medium Range Weather Forecast (ECMWF) Re-Analysis (ERA)-Interim data (Berrisford et al. 2011, Dee et al. 2011) (available at http://apps.ecmwf.int/datasets/data/interim-fullmoda/levtype=sfc/) were used for the analysis. Merged monthly SLA data at $25 \mathrm{~km}$ resolution (1998-2014) were obtained from Ssalto multimission ground segment/Data Unification and Altimeter Combination System (Ssalto/Duacs) processing distributed by Aviso+ (www.aviso.altimetry.fr/en/data/ products/sea-surface-height-products.html). Daily surface wind data at $25 \mathrm{~km}$ resolution for the period 
1998-2014 were also taken from ERA-Interim data (Berrisford et al. 2011, Dee at al. 2011), and monthly means were calculated. We used monthly rainfall data for Kerala State (1998-2014) based on rain gauge measurements (Parthasarathy et al. 1994, 1995), available at the website of the Indian Institute of Tropical Meteorology (IITM), Pune (ftp://www.trop met.res.in/pub/data/rain/iitm-subdivrf.txt). Monthly landing data of Indian oil sardine from Kerala coastal waters for the period 1998-2014 were purchased from the Central Marine Fisheries Research Institute (CMFRI), Kochi.

\subsection{Methodology}

The present study was based on data collected over a period of $17 \mathrm{yr}$, beginning in January 1998 and ending in December 2014, in the Arabian Sea (Fig. 1), in an area that extends $2.5^{\circ}$ westwards from the coastline of Kerala, designated as the South Eastern Arabian Sea (SEAS). Considering the slant in the coastline, the area had an irregular shape so that distance of the offshore boundary to the nearest point on the coastline was always $250 \mathrm{~km}$. The geographic coordinates of the area are approximately $8-13^{\circ} \mathrm{N}$, $73-77^{\circ} \mathrm{E}$ and include the coastal waters of the state of Kerala, India. Each year was divided into 4 seasons based on how the monsoons affect the area (Kumar et al. 1994, Kothawale \& Rupa Kumar 2005): (1) winter (December, January, February), (2) pre-monsoon (March, April, May), (3) southwest monsoon (June, July, August, September) and (4) post-monsoon (October, November).

A multiple linear regression model was set up to assess the influence of physical forcing mechanisms on the phytoplankton biomass on monthly and seasonal scales. Multiple linear regression analysis (MLRA) attempts to model the relationship between 2 or more predictors and a predictand by fitting a linear equation to the observed data. Four physical forcing mechanisms (predictors), viz. alongshore wind stress over the SEAS, rainfall of Kerala State, SST and SLA of SEAS, were used, with chl a concentration as the predictand.

Monthly values of alongshore wind stress, SST and SLA spatially averaged over the SEAS were used for MLRA. Geometric means of the log-transformed chl a $\left(\log _{10} \mathrm{chl}\right)$ data were used to compute the spatial and temporal averages. To remove the negative values present in the $\log$-transformed data, $\log _{10}(\mathrm{chl}+1)$ values were used, as suggested by Parsad (2005), while computing the geometric means.
Alongshore wind stress over the Kerala coast for the period 1998-2014 was computed from ECMWF winds, considering the latitude and coastal angle of each location.

Ekman mass transport was computed from the alongshore wind stress given by:

$$
M_{e}=\tau_{\text {along }} / f
$$

where $M_{e}$ is the Ekman mass transport $\left(\mathrm{kg} \mathrm{m}^{-1} \mathrm{~s}^{-1}\right)$, $\tau_{\text {along }}$ is the alongshore component of wind stress, and $f=2 \Omega \sin \varphi$ is the Coriolis parameter, where $\Omega$ is the Earth's angular frequency and $\varphi$ is the latitude.

Ekman mass transport was computed over the SEAS to describe and understand the coastal upwelling in this region. Negative Ekman mass transport indicates offshore transport of surface waters from near the coast leading to an upwelling situation. Ekman mass transport was not used for MLRA as both alongshore wind stress and Ekman mass transport were primarily derived from the surface winds, which would lead to multicollinearity in the predictors.

MLRA was carried out using monthly as well as seasonal data $(\mathrm{n}=68)$ for the $17 \mathrm{yr}$ period from 1998-2014. The general equation of a multiple linear regression model with 4 predictors and $n$ observations is given by:

$$
\begin{aligned}
Y_{i}= & b_{0}+b_{1} X_{1}+b_{2} X_{2}+b_{3} X_{3}+b_{4} X_{4}+\ldots+\varepsilon_{i} \\
& i=1,2,3,4, \ldots n
\end{aligned}
$$

where $Y$ is the response variable, $b_{0}$ is the intercept, $X_{1}$, $X_{2}, X_{3}, X_{4}$ are the predictors, $b_{1}, b_{2}, b_{3}, b_{4}$ are the partial regression coefficients, and $\varepsilon_{i}$ is the residual, whose magnitude is equal to the difference between the magnitudes of the observed and modelled predictand.

The predictors were then ranked on the basis of the magnitude of their standardized regression coefficients. For this purpose, MLRA was carried out using the standardized anomalies of the predictors. The standardized regression coefficients gave the change in the model output for a given change in the predictive variable, which was measured as a fraction of its standard deviation (Saltelli et al. 2000). The use of standardized coefficients permitted comparisons of predictor-predictand relationships in which the predictors have different units of measurements (Landis 2005). The relation between the standardized regression coefficient and the partial regression coefficient is given by:

$$
\beta_{i}=\frac{b_{i} \sigma_{x_{i}}}{\sigma_{Y}}
$$

where $\sigma_{X_{i}}$ and $\sigma_{Y}$ are standard deviations of the predictor $X_{i}$ and of the predictand $Y$, respectively. 
Pearson's correlation coefficient was calculated between monthly time series data of spatially averaged log chl $a$ and sardine landings with chl a leading by 1 mo to ascertain the influence of phytoplankton biomass on sardine fishery. All statistical analyses were carried out using the $\mathrm{R}$ software package. We checked all regression diagnostics while conducting the analyses.

\section{RESULTS}

Linear correlation analysis between monthly values of pairs of input predictors was performed to check for multicollinearity (Table 1) before proceeding with the MLRA. The predictors were ranked on the basis of the magnitude of their standardized regression coefficients (Table 2). SLA was the most important predictor, followed by alongshore wind stress and SST (all significant at $\alpha=$ 0.05). Kerala rainfall was found to be the least important (ranked 4) among the predictors and was non-significant. The coefficient of determination (COD, $\mathrm{r}^{2}$ ) and adjusted $r^{2}$ (which is a modified version of the COD adjusted for the number of predictors in the fitted line) were 0.80 and 0.79 , respectively. This implied that fluctuations in the predictor variables were able to explain $\sim 80 \%$ of the variability of chl a concentration around its mean (Table 2).

The modelled monthly chl a (Fig. 2) using MLRA, excluding the non-significant parameter rain, was given by:

$$
\begin{aligned}
p_{i}= & 1.45041-0.04303 \mathrm{~T}_{i}-5.33 \times 10^{-5} r i \\
& -2.98494 \tau_{\text {along }_{i}}-0.85989 \zeta_{i}+\varepsilon_{i}
\end{aligned}
$$

where $p=\operatorname{chl} a\left(\mathrm{mg} \mathrm{m}^{-3}\right), \mathrm{T}=\operatorname{SST}\left({ }^{\circ} \mathrm{C}\right)$, $\tau_{\text {along }}=\operatorname{stress}\left(\mathrm{N} \mathrm{m}^{2}\right), \zeta=\operatorname{SLA}(\mathrm{m})$, and $\varepsilon_{i}$ is the residual or error term.

There was no definite pattern among the residuals, which indicates that autocorrelation in the predictors was not a significant factor (see Fig. S1 in the Supplement at

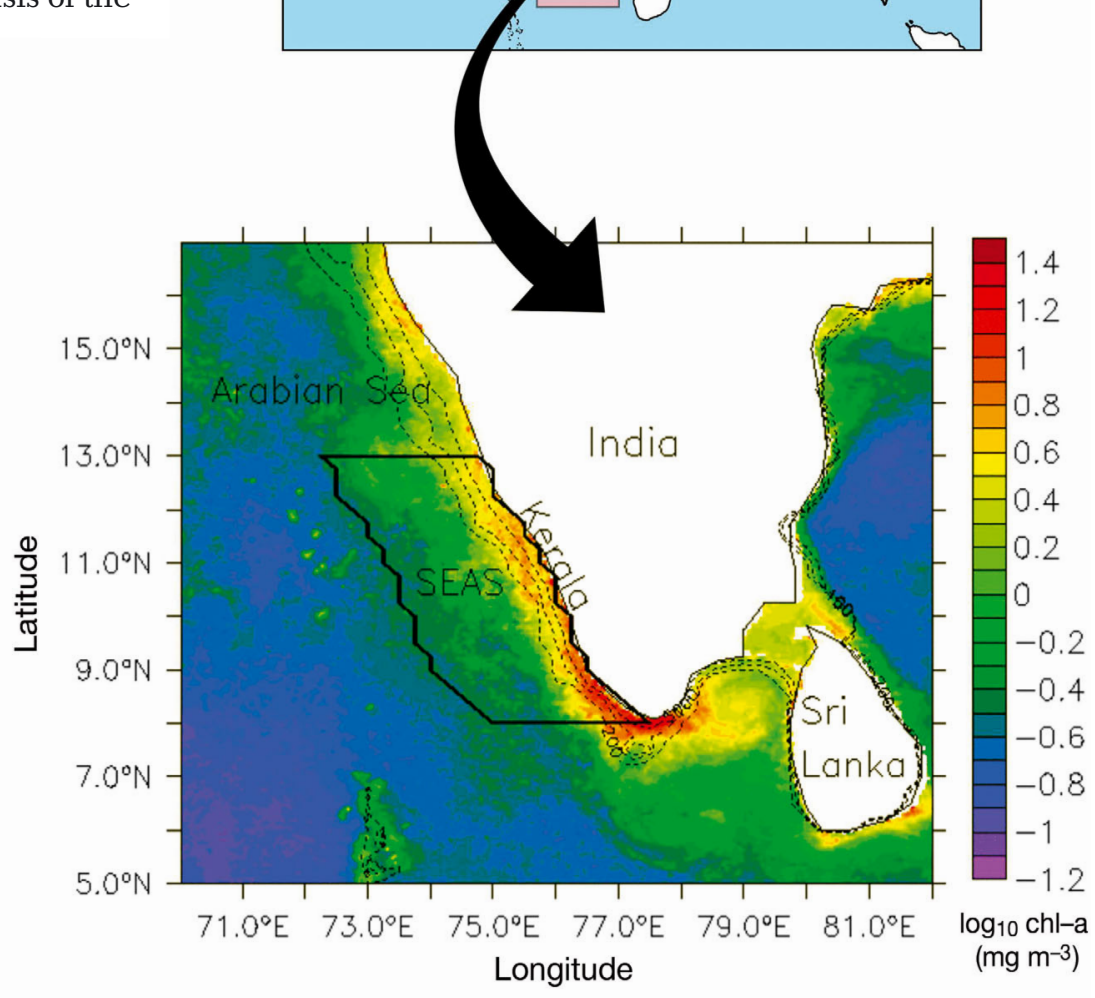

Fig. 1. Study area (irregularly shaped box) designated as the South Eastern Arabian Sea (SEAS) (approximately $8-13^{\circ} \mathrm{N}, 73-77^{\circ} \mathrm{E}$ ), superimposed on Ocean Colour Climate Change Initiative chl a data $\left(\log _{10} \mathrm{chl}\right.$, in $\mathrm{mg}$ $\mathrm{m}^{-3}$ ) for a representative monsoon month (September 2003). Bathymetry lines represent 50, 100 and $200 \mathrm{~m}$ depths

Table 1. Linear correlation coefficients between monthly and seasonal values of pairs of input predictors used for the study. SST: sea surface temperature; SLA: sea level anomaly; Stress: alongshore wind stress; Rain: rainfall in the state of Kerala

\begin{tabular}{|lcccccc|}
\hline Time period & SST vs. Rain & SST vs. Stress & SST vs. SLA & Rain vs. Stress & Rain vs. SLA & Stress vs. SLA \\
\hline Monthly & -0.3025 & 0.3895 & 0.5118 & -0.7236 & -0.6777 & 0.7381 \\
Seasonal & -0.5196 & 0.4664 & 0.5410 & -0.7672 & -0.8748 & 0.7466 \\
\hline
\end{tabular}


Table 2. Multiple linear regression analysis (standardized anomalies) with monthly log-transformed chl $a$ as the predictand and physical parameters as predictors for the period 1998-2014. SLA: sea level anomaly; SST: sea surface temperature; ${ }^{*}$ statistically significant at $\mathrm{p}<0.05$

\begin{tabular}{|lcccccc|}
\hline Predictor variable & Rank & $\begin{array}{c}\text { Value/standardized } \\
\text { regression coefficient }\end{array}$ & SE & $t$ & $\mathrm{p}>|t|$ \\
\hline SLA & 1 & -0.56026 & 0.05353 & -10.46654 & $<0.0001^{*}$ \\
Alongshore wind & 2 & -0.27802 & 0.05311 & -5.23534 & $<0.0001^{*}$ \\
$\quad$ Stress & & -0.26839 & 0.03734 & -7.18716 & $<0.0001^{*}$ \\
SST & 3 & -0.08812 & 0.04885 & -1.80377 & 0.07278 \\
Kerala rainfall & 4 & & & & \\
\hline
\end{tabular}

season $\left(0.2\right.$ to $\left.0.5 \mathrm{mg} \mathrm{m} \mathrm{m}^{-3}\right)$, followed by the post monsoon season. Chl a concentration was highest $\left(8.5 \mathrm{mg} \mathrm{m}^{-3}\right.$ ) along the coast during the southwest monsoon season. The alongshore wind stress was strong and negative (northerly component) during the southwest monsoon season for all years of the study period (Fig. S3). The strength of upwelling, as estimated from the Ekman mass transport, was also negative during www.int-res.com/articles/suppl/m617p137_supp.pdf). The correlation values of only 4 auto-correlations (out of 23) were non-0. The monthly auto-correlation plot also did not exhibit any definite pattern (Fig. S2). As the influence of rain was non-significant in determining the variability of chl a concentration, rain could be ignored in the rest of the analysis.

There was no direct relationship between chl a concentration and sardine landings as revealed by the scatterplot and $\mathrm{r}^{2}$ value (0.00) of monthly log chl a vs. sardine landings (Fig. 3). However, lead-lag correlation analysis between monthly standardized anomalies of log chl $a$ and sardine landings (with chl a leading) for the period January 1998 to December 2014 showed that maximum positive correlations were at 2 and 3 mo lags (Fig. 4$)(+0.26, \alpha=0.01)$. This 2 to 3 mo lag obtained between standardized anomalies of chl $a$ and sardine landings prompted us to reanalyse the data on the basis of a slightly longer time scale, i.e. seasonal.

On a seasonal scale, the lowest concentration of chl a near the coast was observed during the winter

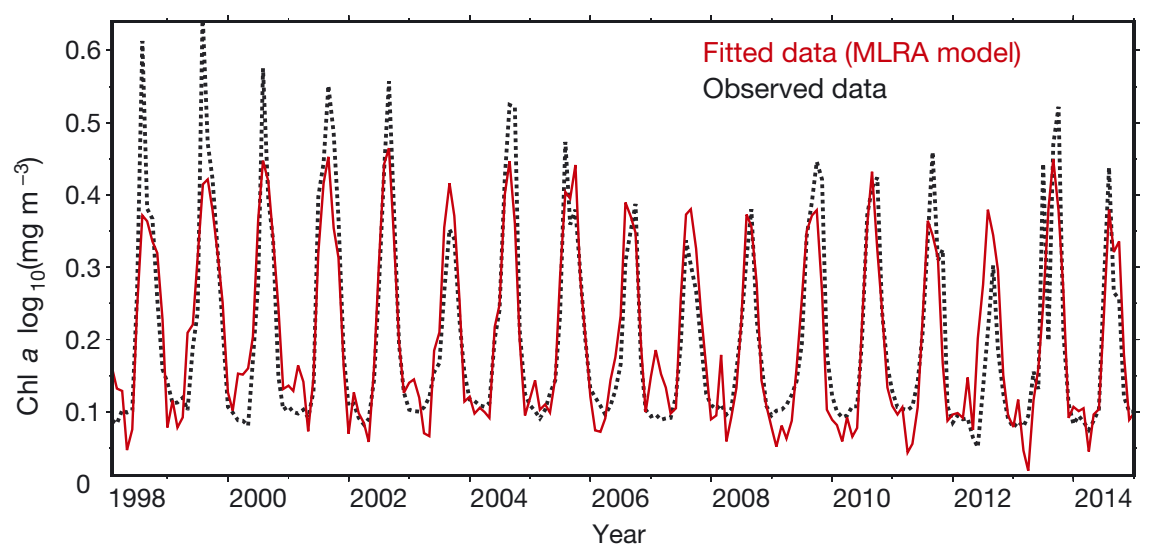

Fig. 2. Modelled monthly chl a concentration in $\log _{10} \mathrm{mg} \mathrm{m}^{-3}$ (red solid line) for the period 1998-2014 based on multiple linear regression analysis (MLRA) plotted against the observed monthly chl a concentration in $\log _{10} \mathrm{mg} \mathrm{m}^{-3}$ (dotted black line) in the South Eastern Arabian Sea (see Fig. 1) the southwest monsoon, indicating offshore water movement, with high negative values of mass transport that reached $-1800 \mathrm{~kg} \mathrm{~m}^{-1} \mathrm{~s}^{-1}$, causing coastal upwelling in the region during the southwest monsoon.

The predictors were ranked on the basis of the magnitude of their standardized regression coefficients (Table 3), which was slightly higher than for the monthly analysis. As in the case of monthly analysis, SLA was the most important variable, followed by alongshore wind stress, SST and Kerala rainfall. In this case, all of the predictors, except rain, were significant $(\alpha=0.05)$. The COD $\left(\mathrm{r}^{2}\right)$ and adjusted $\mathrm{r}^{2}$ were 0.86 and 0.85 , respectively. This implied that the variability in the predictors was able to explain $\sim 85 \%$ of the variability of chl a concentration around its mean (Table 3).

The equation of the modelled seasonal chl a (Fig. 5) using MLRA, excluding the non-significant parameter, rain, is given by:

$$
\begin{aligned}
p_{i}= & 1.16384-0.03415 \mathrm{~T}_{i}+2.26 \times 10^{-5} \mathrm{ri} \\
& -3.10996 \tau_{\text {along }_{i}}-0.6704 \zeta_{i}+\varepsilon_{i}
\end{aligned}
$$

As in the case of monthly analysis, there was no definite pattern among the residuals, indicating the fact that auto correlation in the predictors is not significant (Fig. S4). The correlation values were 0 at all time lags, suggesting randomness. The seasonal autocorrelation plot did not exhibit any definite pattern (Fig. S5).

The linear correlation coefficient between the standardized anomalies of spatially averaged seasonal time series of $\log \mathrm{chl} a$ and sardine landings - with a lag of 1 season-was positive $(\mathrm{r}=$ 0.35 ) and significant at $\alpha=0.01$ (Fig. 6). This showed clearly that 


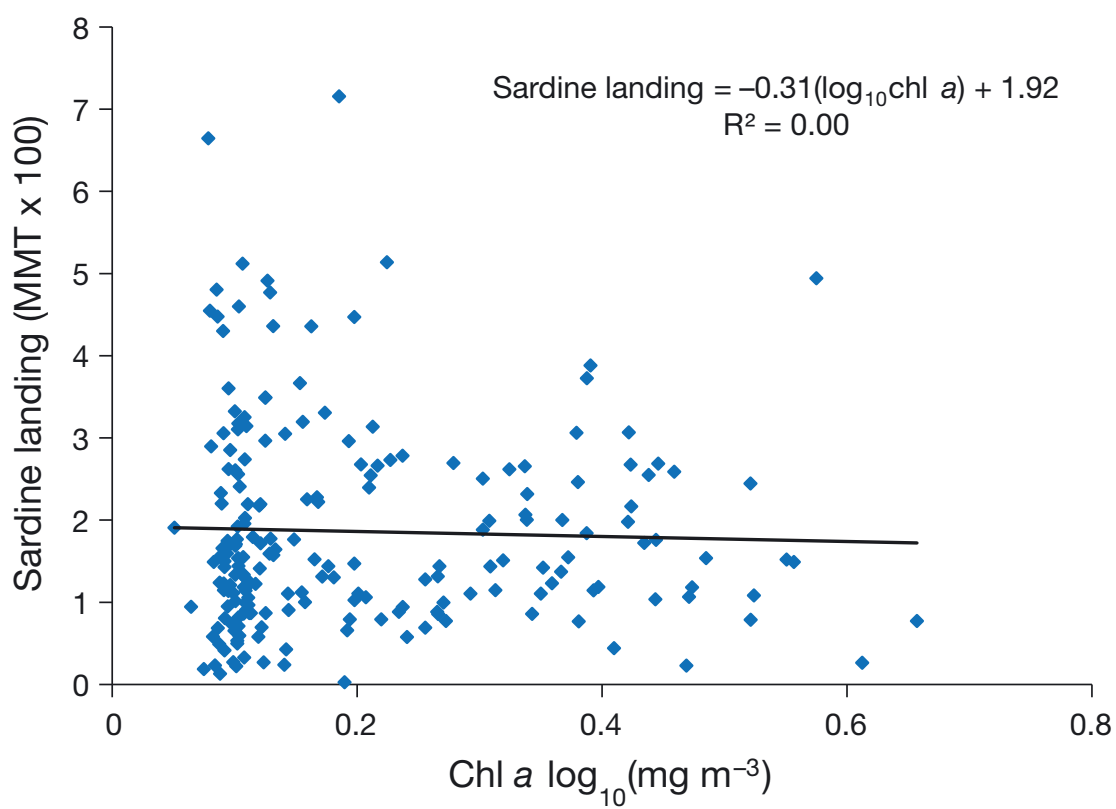

Fig. 3. $\log _{10} \mathrm{chl} \mathrm{a}\left(\mathrm{mg} \mathrm{m}^{-3}\right)$ in the South Eastern Arabian Sea vs. sardine landings (million metric tonnes, MMT) for Kerala on a monthly scale for the time period 1998-2014

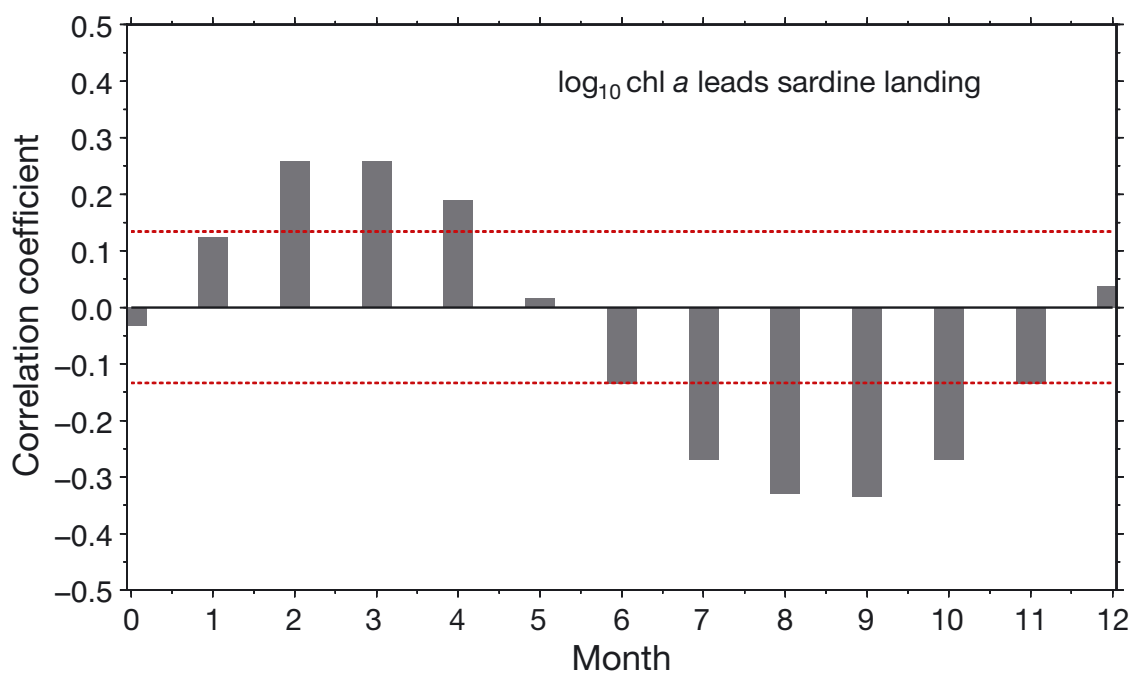

Fig. 4. Lead-lag correlation analysis between standardized anomalies of monthly $\log _{10} \mathrm{chl} a$ and sardine landing (with chl a leading) for the period January 1998 to December 2014. The values above (positive correlations) and below (negative correlations) the red dotted lines are significant at $\alpha=0.05$. The maximum positive correlation is seen at a $2 \mathrm{mo}(+0.26)$ and 3 mo lag $(+0.26)$ (both significant at $\alpha=0.01$ )

the regulation of sardine fishery, noted for its seasonal and inter-annual fluctuations (Fig. 7), is mainly through the seasonal variation in chl a content, which in turn is closely regulated by the seasonal variations in physical parameters.

We tested whether the environmental predictor variables including chl $a$ on a seasonal scale had any direct effect on sardine landings by regressing oceanographic parameters, viz. SLA, SST, alongshore wind stress and $\mathrm{chl} a$, on sardine landings. We found no significant effect, with COD and adjusted $\mathrm{r}^{2}$ being 0.17 and 0.12 , respectively (results not shown) (Table S1).

\section{DISCUSSION}

The North Indian Ocean (NIO) experiences strong seasonally reversing winds associated with the southwest and northeast monsoon seasons. Seasonal variation of such large amplitude is unique and is responsible for the associated seasonal changes in oceanographic and biological properties in the 3 major areas of the NIO, viz. the Somalia basin, Bay of Bengal and Arabian Sea (Shetye et al. 1994). It is based on these variations that the year has been divided into 4 seasons of unequal durations (Kumar et al. 1994), as done in the present study. In concurrence with the peculiar oceanographic features prevalent at the seasonal scale in the SEAS, a higher COD $\left(r^{2}=0.86\right)$ was obtained when we used seasonal data instead of monthly data in the MLRA. This emphasizes the relevance of seasonal fluctuations in chl $a$ and their impact on the annual fluctuations in the fishery of Indian oil sardines. Shankar \& Shetye (1997) showed that upwelling in the band from $9-13^{\circ} \mathrm{N}$ is under the combined influence of local winds and the upwelling mode of the remotely forced Kelvin and Rossby waves. Strong negative SLAs, which are signatures of upwelling, were found throughout the study period from February to July. During the southwest monsoon, surface winds blow parallel to the Kerala coast, inducing an offshore component of surface Ekman transport. However, the local wind movement is not adequate to explain the well defined seasonality in upwelling. Along the west 
Table 3. Multiple linear regression analysis (standardized anomalies) with seasonal log-transformed chl $a$ as the predictand and physical parameters as predictors for the period 1998-2014. SLA: sea level anomaly, SST: sea surface temperature; ${ }^{*}$ statistically significant at $\mathrm{p}<0.05$

\begin{tabular}{|lccccc|}
\hline $\begin{array}{l}\text { Predictor } \\
\text { variable }\end{array}$ & Rank & $\begin{array}{c}\text { Value/standardized } \\
\text { regression coefficient }\end{array}$ & SE & $t$ & $p>|t|$ \\
\hline SLA & 1 & -0.48044 & 0.1032 & -4.65551 & $<0.0001^{*}$ \\
$\begin{array}{l}\text { Alongshore wind } \\
\quad 2\end{array}$ & -0.31676 & 0.0768 & -4.12463 & $<0.0001^{*}$ \\
SST & 3 & -0.23207 & 0.05719 & -4.05816 & $<0.0001^{*}$ \\
Kerala rainfall & 4 & 0.03472 & 0.10549 & 0.32914 & 0.74314 \\
\hline
\end{tabular}

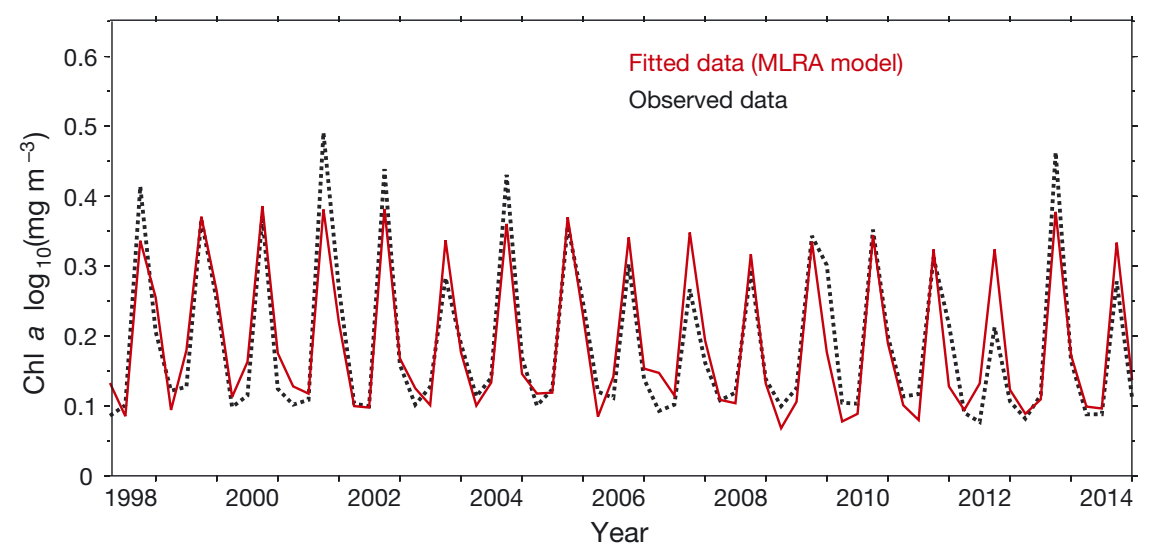

Fig. 5. Modelled seasonal chl a concentration in $\log _{10} \mathrm{mg} \mathrm{m}^{-3}$ (red solid line) for the period 1998-2014 based on multiple linear regression analysis (MLRA) plotted against the observed seasonal log chl a concentration (dotted black line) in the South Eastern Arabian Sea (see Fig. 1)

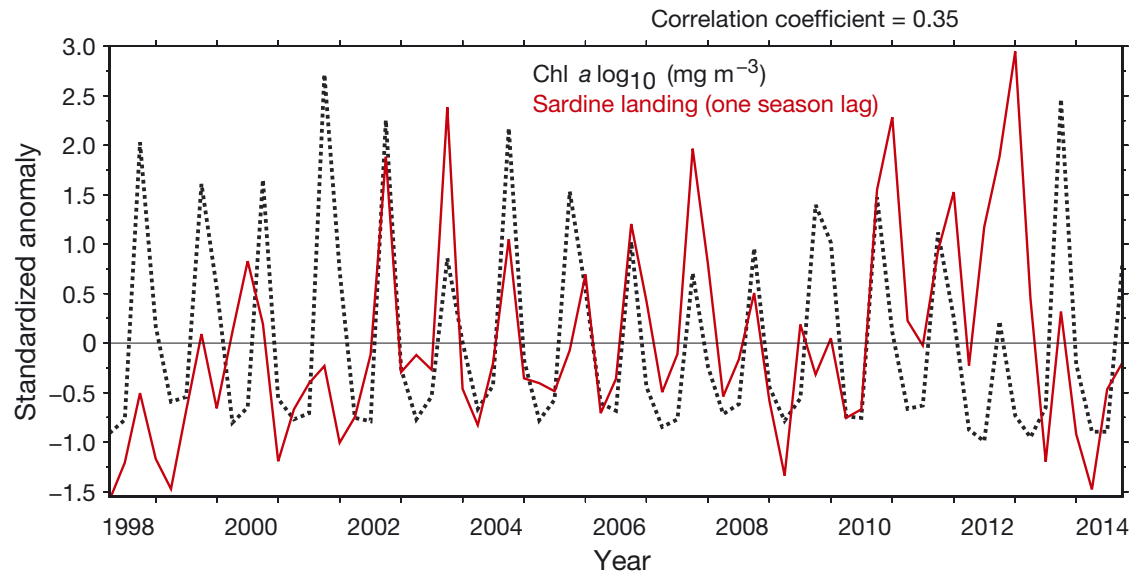

Fig. 6. Standardized anomalies of spatially averaged seasonal chl a $\left(\log _{10} \mathrm{mg} \mathrm{m}^{-3}\right.$; black dotted line) and sardine landings (million metric tonnes; red line) in Kerala with a lag of 1 season for the period 1998-2014 ( $\mathrm{r}=0.35)$. Chl $a$ is leading the sardine landings by 1 season

coast of India, upwelling is initiated by basin-scale winds rather than by local wind forcing (Smitha 2010).
As the MLRA ranking of the present study indicates, the surface chl a concentration in the SEAS is affected by physical mechanisms, such as offshore Ekman transport, alongshore wind stress and SLA, that, in turn, are influenced by local winds as well as remote forcing mechanisms. Even though the sardine fishery is restricted to the inshore waters of Kerala, the influence of environmental properties over the entire eastern Arabian Sea is responsible for fluctuations in the fishery. Hence, data from a region covering waters up to $250 \mathrm{~km}$ from the shore along the Kerala coast were selected for the study. Previous studies attempted to explain fluctuations of the fishery in terms of localized environmental properties and did not consider remote forcing mechanisms. Here we looked into regional-scale processes that influence the sardine fishery in Kerala waters. The higher COD (0.86) and adjusted $\mathrm{r}^{2}(0.85)$ obtained in the seasonal MLRA show that seasonal fluctuations in environmental variables were able to explain seasonal changes in chl a concentration better than the monthly values. The critical roles played by Ekman transport and alongshore wind stress in initiating the upwelling off the south west coast of India are well documented (Smitha et al. 2008, Jayaram et al. 2010).

Longhurst \& Wooster (1990) were of the opinion that marked inter-annual variations in sardine catches at Kochi, Kerala, are probably tied to variations in physical forcing mechanisms such as strength and onset of monsoon and sea level variability. However, the MLRA results of the present study showed that, among the variables tested, the strength of monsoon rainfall did not have a significant influence $(p>0.05)$ on chl a concentration (Tables 2 


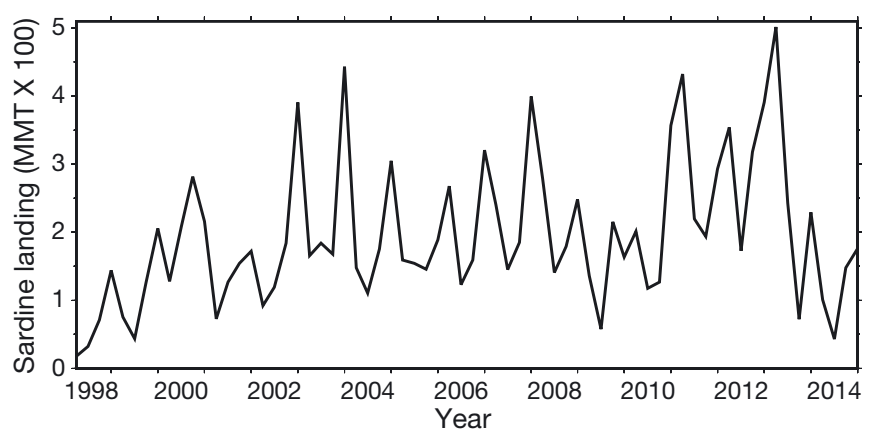

Fig. 7. Seasonal landings (in million metric tonnes, MMT) of Indian oil sardine for the state of Kerala for the time period 1998-2014

\& 3). According to Jayaram (2011), the influence of rainfall is seen only on SST in the SEAS and not on chl a directly. Sensitivity of Indian oil sardines to temperature is well documented, and the fish prefer a temperature range of $27-29^{\circ} \mathrm{C}$ (Chidambaram 1950, Vivekanandan et al. 2009). In the present study, $53 \%$ of the seasons (36 out of 68) had average SSTs favourable for the existence of oil sardines, whereas 32 $(47 \%)$ of the seasons had temperatures above the preferred range. There were no seasons with temperatures below $27^{\circ} \mathrm{C}$. This raised a suspicion whether SST had a direct influence on the sardine fishery of the study area (rather than an indirect influence through its effect on chlorophyll), which was tested using Pearson's linear correlation analysis between the favourable and unfavourable temperature ranges against chl $a$, on a seasonal scale, on sardine landings. In the case of the favourable temperature range $\left(27-29^{\circ} \mathrm{C}\right)$, the linear correlation coefficient was 0.14 (36 seasons), whereas for the unfavourable temperature range $\left(>29^{\circ} \mathrm{C}\right)$, the correlation coefficient was -0.62 (32 seasons). This shows that temperature preference for sardine is a physiological matter, independent of food supply; the fish have to eat, and they will find the food where they can. In the study area selected for reanalysis of data, the seasonal temperature range was between 27 and $30.7^{\circ} \mathrm{C}$. The fish may have had difficulties at the highest temperature $\left(30.7^{\circ} \mathrm{C}\right)$, which is marginally outside the preference range, but the lowest temperature $\left(27^{\circ} \mathrm{C}\right)$ was still within the preference range for sardine. Although an inverse relation between SST and chl a was observed throughout the study, the fish would not have been stressed by low temperature at any time. The lowest SST was found during the southwest monsoon, which also had the highest concentration of chl a during the entire duration of the study. Incidentally, the southwest monsoon was the time of spawning of sardines, and provided ample food supply to the growing larvae.
Most earlier studies attempted to establish a relation between interannual variations in environmental parameters and the sardine fishery (Longhurst \& Wooster 1990, Krishnakumar \& Bhat 2008, Vivekanandan et al. 2009). However, only the study by George et al. (2012) hypothesized that the variation in sardine population dynamics is closely related to the life cycle of the animal and is linked to the food availability during the growing stages of the population. Indian oil sardines have their peak spawning activity during the southwest monsoon (Nair 1960). They have a fractional spawning system that depends on the release of multiple egg batches at intervals (Cunha et al. 1992). Differential growth rates for the different broods arise from early spawning and late spawning in the same season (Antony Raja 1970). The earlier brood spawned in June-July has a high rate of growth, reaching $105 \mathrm{~mm}$ in $8 \mathrm{wk}$, whereas those spawned in July-August attain the same length in $10 \mathrm{wk}$. George et al. (2012) stated that sardine catch is dominated by zero year class individuals measuring $\leq 140 \mathrm{~mm}$ in total length that spawned during the earlier spawning period starting from May. As sardines are predominantly herbivorous, variation in food availability can be assessed from variation in chl a concentration.

Onset and progress of the southwest monsoon are marked by the occurrence of diatom blooms along the Kerala coast (George et al. 2012, Nashad et al. 2017). George et al. (2012) asserted that an early spawning and a time lag in development of food (through a break in the monsoon or upwelling) would be detrimental to sardine recruitment. The landing data of Indian oil sardine clearly indicate an inter-annual fluctuation, but the fish production over the last few decades has shown an increasing trend. Taking into consideration that stock abundance of oil sardines is directly related to landings, or that there is little change between years in the harvest of these resources, with at least a dozen diverse gear and craft combinations in inshore waters (Sathiadhas 2006, Kripa et al. 2015), a maximum positive correlation at 2 and 3 mo lags $(+0.26$, statistically significant at $\alpha=$ 0.01 ) was obtained for the lead-lag correlation analysis between chl $a$ and sardine landings (with chl $a$ leading) on a monthly scale. According to Mohanty et al. (2005), the success of the oil sardine fishery depends mainly on the recruitment strength of early juveniles (50-100 $\mathrm{mm}$ ) during post monsoon months. They found that from October onwards, recruitment of juveniles intensifies and fish of a wide range in length are observed in the catches. Remya et al. (2013) also established that the post monsoon catches 
are dominated by 'immature' stage I and stage II fish, which range from 112-193 $\mathrm{mm}$ in length. These observations, coupled with the fractional spawning and differential growth rates for different broods, explain the $2-3$ mo lag that was obtained by means of Pearson's correlation (lead-lag) analysis between chl a and sardine landings. On a seasonal scale also, this 2-3 mo lag relation is relevant, as our seasons are of different durations, from 2-4 mo. Our results are consistent with the Hjort-Cushing match-mismatch hypothesis (Hjort 1914, Cushing 1974, 1990) that the survival rate of fish larvae is a function of the synchrony between timing of hatching of eggs and initiation of the spring phytoplankton bloom (Platt et al. 2003). Thus, the chl a bloom in the southwest monsoon season supports a successful fishery in the post monsoon season which follows after a lag of 2-3 mo.

At the time of writing, no management plans exist for the sardine fishery in India. The Indian oil sardine is reported to have inter-annual fluctuations in landings that depend on environmental variability rather than fishing efforts. A well-equipped fleet with sufficient infrastructure and manpower to exploit the existing fish biomass is available (Jayaprakash \& Pillai 2000). The environmental processes responsible for the occurrence of phytoplankton blooms, as evidenced by the enhancement of chl a concentration, start 2-3 mo (March-April) before the sardine spawning (June-July). Thus, assuming that any future management plan would be ecosystem-based, magnitudes of environmental drivers on chl $a$, that are readily and freely available, could be used to estimate the potential quantity of sardines available for harvest in a given year. Such forecasts could be given with at least 3 mo notice. In the case of zero year class fisheries such as sardines, with short life-spans and rapid turnover of generations, it is advisable to study on smaller time scales, rather than using inter-annual variability, to elucidate the principal causative factors responsible for fluctuations in the fishery. Sardines are fish of high nutritive and economic value. Thus, prior knowledge of possible low landings would help the fishermen decide whether to target other species, thereby managing the fishery in a better way. Even temporary collapses of small pelagic fish such as sardines can have large impacts on the ecosystem, demanding a rational management of these fish. In the present study, we have examined the dynamics of the recruitment of sardines to the fishery in Kerala waters on a time scale which, even though referred to as seasonal, does not imply standard astronomical seasons, but rather refers to sequential periods from 2 to 4 mo each that are important in the life cycle and ecology of the fish (in other words, to ecological seasons). Such an approach is a first step towards management of this commercially important species

Finally, we recognize that our approach has its own limitations. We did not take into account the variability of the sub-surface chlorophyll, which cannot be measured using satellite remote sensing. The chlorophyll concentrations in the coastal regions are also influenced by the variability of various physical and biological variables such as zooplankton, nutrient availability and dissolved oxygen content, which were not included in our analysis. Owing to the presence of persistent clouds, the data gap in the OC-CCI chl a is highest during the southwest monsoon among the 4 seasons considered. It is also during the same season that surface chl $a$ is observed to have maximum magnitude. This is an inherent limitation of the ocean colour data from remote sensing. The correlation coefficient of 0.35 between sardine landing and chl a on a seasonal basis serves to explain only $12 \%$ variability in the fishery data, but the result could be viewed as a small but important step forward in the management of a dynamic fishery, in this case by forewarning of potentially low landings when chlorophyll concentrations during the growing season are anomalously low. Ecosystem-based management implies that we examine all possible time series of variability, including annual and multi-decadal fluctuations.

In conclusion, our results suggest that the season preceding phytoplankton biomass has a direct positive relation with the landings of Sardinella longiceps in the coastal waters of SEAS by influencing the physiology during critical periods of its life cycle. This supports our hypothesis that any variation in chl a concentration caused by environmental fluctuations will impact the sardine catch in the following season and thereby the annual landings. Further, the relative importance or ranking of the physical variables that affect chl a concentration could be used as a guide to modelling and predicting the sardine fishery of SEAS.

Acknowledgements. The first 3 authors gratefully acknowledge the infrastructural and financial support provided by the Nansen Environmental and Remote Sensing Center (NERSC), Bergen, Norway. A.S. is thankful for further financial assistance from DST-SERB. We appreciate the support and encouragement received from the Director of the Central Marine Fisheries Research Institute (ICAR-CMFRI), India, and acknowledge the contributions of the team of the Jawaharlal Nehru Science Fellowship (JNSF-SERB DST Government of India) Lab - Fishery Resources Assessment Division, ICAR-CMFRI, in improving the quality of the work. We also thank Dr. Eldho Varghese, ICAR-CMFRI, for guidance on the statistical analyses. 


\section{LITERATURE CITED}

Antony Raja BT (1970) Estimation of age and growth of the Indian oil sardine, Sardinella longiceps Val. Indian J Fish $17: 26-42$

Bakun A, Roy C, Lluch-Cota S (1998) Coastal upwelling and other processes regulating ecosystem productivity and fish production in the western Indian Ocean. In: Sherman K, Okemwa E, Ntiba MJ (eds) Large marine ecosystems of the Indian Ocean: assessment, sustainability and management. Blackwell Sciences Inc, Malden, MA, p 103-141

Berrisford P, Dee D, Poli P, Brugge R and others (2011) The ERA-Interim archive [Version 2.0]. ECMWF, Shinfield Park, Reading

Chidambaram K (1950) Studies on the length frequency of oil sardine, Sardinella longiceps Cuv. \& Val. and on certain factors influencing their appearance on the Calicut coast of the Madras residency. Proc Indian Acad Sci 31: 252-286

Cunha ME, Figueiredo I, Farinha A, Santos M (1992) Estimation of sardine spawning biomass off Portugal by the daily egg production method. Bol Inst Esp Oceanogr 8: 139-153

Cushing DH (1974) The natural regulation of fish populations. In: Harden Jones FR (ed) Sea fisheries research. Elek Science, London, p 399-412

Cushing DH (1990) Plankton production and year-class strength in fish populations: an update of the matchmismatch hypothesis. Adv Mar Biol 26:249-294

Dee DP, Uppala SM, Simmons AJ, Berrisford P and others (2011) The ERA-Interim reanalysis: configuration and performance of the data assimilation system. Q J R Meteorol Soc 137:553-597

Frank KT, Petrie B, Shackell NL, Choi JS (2006) Reconciling differences in trophic control in mid-latitude marine ecosystems. Ecol Lett 9:1096-1105

Frederiksen M, Edwards M, Richardson AJ, Halliday NC, Wanless S (2006) From plankton to top predators: bottom-up control of a marine food web across four trophic levels. J Anim Ecol 75:1259-1268

George G, Meenakumari B, Raman M, Verlecar X (2012) Remotely sensed chlorophyll: a putative trophic link for explaining variability in Indian oil sardine stocks. J Coast Res 28:105-113

Hjort J (1914) Fluctuations in the great fisheries of Northern Europe viewed in the light of biological research. Rapp P-V Réun Cons Perm Int Explor Mer 20:1-228

Jackson T, Sathyendranath S, Mélin F (2017) An improved optical classification scheme applied to ocean colour ECV. Remote Sensing Environ 203:152-161

Jayaprakash AA, Pillai NGK (2000) The Indian oil sardine. In: Pillai VN, Menon NG (eds) Marine fisheries research and management. Central Marine Fisheries Research Institute, Cochin, p 259-281

Jayaram C (2011) Remote sensing the signatures of upwelling in South Eastern Arabian Sea. PhD dissertation, Cochin University of Science and Technology, Kochi

Jayaram C, Chacko N, Joseph KA, Balchand AN (2010) Interannual variability of upwelling indices in the southeastern Arabian Sea: a satellite based study. Ocean Sci J 45:27-40

Kothawale DR, Rupa Kumar K (2005) On the recent changes in surface temperature trends over India. Geophys Res Lett 32:L18714
Kripa V, Prema D, Jeyabaskaran R, Khambadkar LR and others (2015) Inter-annual variations of selected oceanographic parameters and its relation to fishery of small pelagics off Kochi, southwest coast of India. J Mar Biol Assoc India 57:52-57

Krishnakumar PK, Bhat GS (2008) Seasonal and interannual variations of oceanographic conditions off Mangalore coast (Karnataka, India) during 1995-2004 and their influences on pelagic fishery. Fish Oceanogr 17:45-60

Krishnakumar PK, Mohamed KS, Asokan PK, Sathianandan TV and others (2008) How environmental parameters influenced fluctuations in oil sardine and mackerel fishery during 1926-2005 along the south-west coast of India. Mar Fish Inf Serv T\&E Ser 198:1-5

Kumar KR, Kumar KK, Pant GB (1994) Diurnal asymmetry of surface temperature trends over India. Geophys Res Lett 21:677-680

KLandis RS (2005) Standardized regression coefficients. Encyclopedia of statistics in behavioral science. https://doi. org/10.1002/0470013192.bsa639

*Longhurst AR, Wooster WS (1990) Abundance of oil sardine (Sardinella longiceps) and upwelling in the south west coast of India. Can J Fish Aquat Sci 47:2407-2419

Madhupratap MS, Shetye R, Nair KNV, Nair SRS (1994) Oil sardine and Indian mackerel, their fishery problems and coastal oceanography. Curr Sci 66:340-348

Manjusha U, Jayasankar J, Remya R, Ambrose TV, Vivekanandan E (2013) Influence of coastal upwelling on the fishery of small pelagics off Kerala, south west coast of India. Indian J Fish 60:37-43

Mohanty PK, Khora SS, Panda US, Mohapatra GN, Mishra P (2005) An overview of sardines and anchovies fishery along the Indian coasts. Department of Marine Sciences, Berhampur University, Berhampur

Nair RV (1960) Synopsis of the biology and fishery of the Indian sardines. Proc World Sci Meeting on Biology of Sardines and related species. FAO, Rome, p 239-414

Nashad M, Menon NN, Joseph AC, Pettersson LH, Menon NR (2017) First report of Leptocylindrus sp. bloom in the coastal waters of Kerala (southeast Arabian Sea). J Mar Biol Assoc India 59:28-33

* Parsad R (2005) Transformation of data. In: Parsad R, Srivastava R, Gupta VK (eds) Design and analysis of agricultural experiments. Indian Agricultural Statistics Research Institute, New Delhi, p 637-647

*Parthasarathy B, Munot AA, Kothawale DR (1994) All India monthly and seasonal rainfall series: 1871-1993. Theor Appl Climatol 49:217-224

Parthasarathy B, Munot AA, Kothawale DR (1995) Monthly and seasonal rainfall series for all-India homogeneous regions and meteorological subdivisions: 1871-1994. RR065. Indian Institute of Tropical Meteorology, Pune

Pettersson LH, Pozdnyakov D (2012) Monitoring of harmful algal blooms. Springer, Praxis Publishing, Chichester

* Platt T, Fuentes-Yaco C, Frank KT (2003) Spring algal bloom and larval fish survival. Nature 423:398-399

Platt T, Sathyendranath S, White GN III, Fuentes-Yaco C, Zhai L, Devred E, Tang C (2010) Diagnostic properties of phytoplankton time series from remote sensing. Estuaries Coasts 33:428-439

Remya R, Vivekanandan E, Manjusha U, Nair PG (2013) Seasonal variations in the diet of Indian oil sardine Sardinella longiceps Valenciennes off Cochin, Kerala. Indian J Fish 60:55-59

Saltelli A, Chan K, Scott M (2000) Handbook of sensitivity 
analysis. Probability and Statistics Series. John Wiley \& Sons Publishers, New York, NY

Sathiadhas R (2006) Socio-economic scenario of marine fisheries in India - an overview. In: Kurup BM, Ravindran K (eds) Sustain fish. School of Industrial Fisheries, CUSAT, Cochin, p 84-101

Sathyendranath S, Brewin RJW, Jackson T, Melin F, Platt T (2017) Ocean-colour products for climate-change studies: What are their ideal characteristics? Remote Sens Environ 203:125-138

Sathyendranath S, Grant M, Brewin RJW, Brockmann C and others (2018) ESA Ocean Colour Climate Change Initiative (Ocean_Colour_cci): Version 3.1 Data. Centre for Environmental Data Analysis. http://catalogue.ceda.ac. uk/uuid/9c334fbe6d424a708cf3c4cf0c6a53f5

Schwartzlose RA, Alheit J, Bakun A, Baumgartner TR and others (1999) Worldwide large-scale fluctuations of sardine and anchovy populations. S Afr J Mar Sci 21:289-347

Shankar D, Shetye SR (1997) On the dynamics of Lakshad-

Editorial responsibility: Verena Trenkel (Guest Editor), Nantes, France weep high and low in the South Eastern Arabian Sea. J Geophys Res 102:12551-12562

Shetye SR, Gouveia DA, Shenoi S (1994) Circulation and water masses of the Arabian Sea. Proc Indian Acad Sci 103:107-123

Smitha BR (2010) Coastal upwelling of the South Eastern Arabian sea: an integrated approach. PhD dissertation, Cochin University of Science and Technology, Kochi

* Smitha BR, Sanjeevan VN, Vimal Kumar KG, Ravichandran C (2008) On the upwelling off the southern tip and along the west coast of India. J Coast Res 24:95-102

Vivekanandan E, Rajagopalan M, Pillai NGK (2009) Recent trends in sea surface temperature and its impact on oil sardine. In: Agarwal PK (ed) Global climate change and Indian agriculture. Case studies from ICAR Network project. ICAR, New Delhi, p 89-92

* Worm B, Myers RA (2003) Meta-analysis of cod-shrimp interactions reveals top-down control in oceanic food webs. Ecology 84:162-173

Submitted: August 25, 2017; Accepted: October 30, 2018 Proofs received from author(s): December 11, 2018 